different from that of tailed bacteriophages. Although this is possible, it is perhaps premature to generalize. Kauffman et al. examined only Vibrionaceae. Moreover, some tailed marine bacteriophages have wide host ranges ${ }^{11}$.

How did these viruses evade previous detection in highly studied systems? The authors note that this could be because some standard viral isolation approaches for lab culture and DNA analysis have sampling biases, which might arise if a virus particle contains lipid, as seems to be the case for the autolykiviruses.

Chloroform treatment is commonly used to disrupt cell membranes as a way of limiting bacterial contamination during bacteriophage isolation; however, Kauffman et al. report that chloroform can inactivate autolykiviruses. And when a density-gradient centrifugation approach is used to isolate bacteriophages for DNA-sequence analysis, autolykiviruses are found in a low-density fraction separate from the heavier fraction that contains most bacteriophages (and which is thus usually analysed). An additional snag is the presence of protein covalently bound to autolykiviral DNA that necessitates treatment with a protease enzyme for DNA extraction, an uncommon step in standard large-scale virus-sequencing studies. These technical obstacles should be considered both in future surveys and in the interpretation of existing ones.

Are these autolykiviruses the missing nontailed marine viruses? Although this discovery certainly illuminates the value of analysing host-virus systems found in marine environments ${ }^{11-13}$, the Autolykiviridae constitutes just a fraction of the missing non-tailed viruses the authors' quantitative isolation technique demonstrated that only around $7 \%$ of the viruses (18 out of 241) cultured on Vibrionaceae were autolykiviruses. Autolykivirusrelated sequences are found in DNA sequences of many phyla of bacteria and archaea (another single-celled group that lacks a nucleus). This suggests that other Autolykiviridae-like viruses exist, although the authors were unable to estimate the frequency of autolykivirus-like sequences. They observed that the autolykiviral infection cycle was slower than that of tailed bacteriophages in laboratory experiments, which might imply a disproportionately lower effect of autolykiviruses when viruses compete in nature.

Because the autolykiviruses were found by studying hosts representing only a tiny portion of the overall diversity of marine bacteria, the use of hosts from multiple phyla might reveal other viral groups previously missed. Modified experimental protocols might capture those excluded for the same types of technical reason that prevented autolykiviral identification. Finding previously unknown viral groups is crucial, because large-scale DNA surveys across organisms require reference sequences, and this study points us in the right direction. Luckily, a method is available for extracting viral DNA that avoids the problematic step of density gradients and includes a proteasetreatment step ${ }^{14}$. This puts the search for further non-tailed viral relatives, and the quantitative study of their effect on marine microbial systems, within reach.

Julio Cesar Ignacio-Espinoza and

Jed A. Fuhrman are in the Department of Biological Sciences and at the Wrigley Institute for Environmental Studies, University of Southern California, Los Angeles,

California 90089, USA.

e-mail:fuhrman@usc.edu

1. Cobián Güemes, A. G. et al. Annu. Rev. Virol. 3, 197-214 (2016)

2. Suttle, C. A. Nature 437, 356-361 (2005).

3. Børsheim, K. Y., Bratbak, G. \& Heldal, M. Appl. Environ. Microbiol. 56, 352-356 (1990).
4. Wommack, K. E., Hill, R. T., Kessel, M., Russek-Cohen, E. \& Colwell, R. R. Appl. Environ. Microbiol. 58, 2965-2970 (1992).

5. Brum, J. R., Schenck, R. O. \& Sullivan, M. B. ISME J. 7, 1738-1751 (2013).

6. Fuhrman, J. A. Nature 399, 541-548 (1999).

7. Kauffman, K. M. et al. Nature 554, 118-122 (2018)

8. Holmfeldt, K. et al. Proc. Natl Acad. Sci. USA 110, 12798-12803 (2013)

9. Hug, L. A. et al. Nature Microbiol. 1, 16048 (2016).

10.Krupovic, M. \& Koonin, E. V. Proc Natl Acad. Sci. USA 114, E2401-E2410 (2017).

11.Sullivan, M. B., Waterbury, J. B. \& Chisholm, S. W. Nature 424, 1047-1051 (2003)

12.Kang, I., Oh, H.-M., Kang, D. \& Cho, J.-C. Proc. Natl Acad. Sci. USA 110, 12343-12348 (2013)

13.Zhao, Y. et al. Nature 494, 357-360 (2013).

14.Steward, G. F. \& Culley, A. I. in Manual of Aquatic Viral Ecology 154-165 (Assoc. Sci. Limnol. Oceanogr., 2010).

15.Comeau, A. M. \& Krisch, H. M. Mol. Biol. Evol. 25, 1321-1332 (2008)

This article was published online on 24 January 2018.

\title{
PALAEOCLIMATE
}

\section{Pollen weighs in on a climate conundrum}

\begin{abstract}
Simulations by climate models show that Earth warmed during the Holocene epoch, whereas ocean sedimentary cores suggest that global cooling occurred. An analysis of fossil pollen samples now sides with the models. SEE LETTER P.92
\end{abstract}

\section{JEREMY D. SHAKUN}

$\mathrm{T}$ The iconic 'hockey stick' graph shows that global warming of $1{ }^{\circ} \mathrm{C}$ during the past century has reversed a 2,000-year-long, modest cooling trend ${ }^{1}$. But longer trends are also of interest: how did temperatures change during the rest of the Holocene epoch, which began about 11,700 years ago at the end of the last ice age, and during which human civilization arose? It was previously thought that the Holocene coincided with long-term global cooling ${ }^{2}$, but on page 92, Marsicek et al. ${ }^{3}$ present a reconstruction of Holocene temperatures from North America and Europe that indicate a long-term warming trend. The findings cast light on how well climate models and proxies agree with each other and reproduce the ancient climate, the drivers of climate change during interglacial periods, and the geological context for the current state of the climate.

Global temperature might seem a simple quantity, but its changes during the Holocene are not easy to deduce theoretically. The factors that had the largest effect on climate during this period were gradual variations in the tilt and wobble of Earth's axis. These orbital changes altered the insolation (the amount of sunlight received) for different regions of the world and the seasonal patterns of this insolation. However, such orbital variations do not change the global mean annual insolation, and thus would not affect global temperature if the climate system responded in a linear way.

But the climate system's response might have been nonlinear - for instance, if responses occurred more strongly in some areas or at some times of the year than others ${ }^{4}$. Indeed, it is well established that orbital forcing gave rise to the glacial-interglacial cycles of the past few million years, with most of the change in global temperature typically being attributed to feedbacks associated with ice sheets and greenhouse gases. Climate models suggest that these two factors would also have dominated global temperature during the Holocene: retreating ice sheets early in the epoch, and rising levels of greenhouse gases later on, both nudged the planet towards warmer temperatures ${ }^{5}$.

The first reconstruction ${ }^{2}$ of Holocene global temperatures to be derived from the geological record was based mainly on sea surface temperatures obtained from the analysis of marine sediment cores. In contrast to the models, this showed that the early Holocene was the warmest part of the epoch, and that global temperature has dropped by about $0.7^{\circ} \mathrm{C}$ during the past 5,000 years. The disparity between models and the reconstruction has been dubbed the 'Holocene temperature conundrum ${ }^{5}$, and two possible explanations 


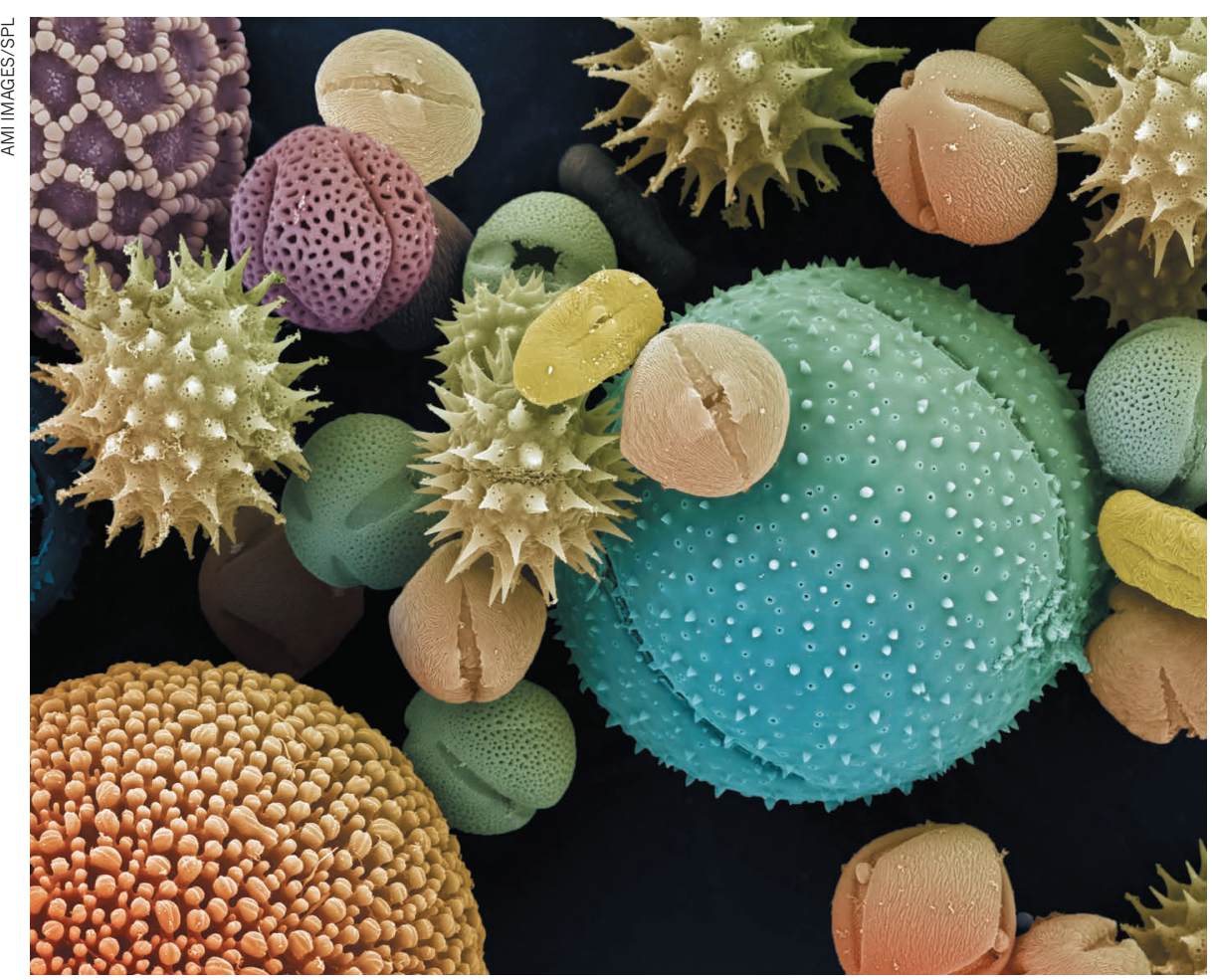

Figure 1 | Pollen grains. Marsicek et al. ${ }^{3}$ have analysed pollen samples preserved in lake sediments from North America and Europe to reconstruct temperatures since the end of the last ice age. The colours used in this micrograph are false.

have been put forward. It could be that proxies of sea surface temperature used in the analysis of the marine cores are biased towards temperatures that occur at certain times of the year, and thus record orbitally driven changes in seasonal temperature, whereas the mean annual temperature changed only little. Or perhaps climate models do not accurately simulate nonlinear feedback responses to seasonal insolation that are stronger at some times of the year than others, and thus yield mean annual temperature changes.

Marsicek et al. revisit this problem by producing a new temperature reconstruction based on analyses of pollen grains (Fig. 1) preserved in lake sediments, often referred to as fossil pollen. Pollen-based reconstructions can potentially resolve mean annual and seasonal trends because each plant species has its own sensitivity to winter cold and summer warmth. For example, the populations of some species decline above or below certain temperatures, and so the abundance of pollen from such species in fossil samples can be used as a proxy of temperature.

The authors note that cooling recorded in cores from the North Atlantic Ocean was the main driver of the drop in mean global temperature observed in the previously reported Holocene reconstruction ${ }^{2}-$ in other words, the North Atlantic is the chief source of the conundrum. The authors therefore compiled and statistically analysed hundreds of pollen records from North America and Europe to see whether the cooling trend holds on either side of the North Atlantic. They find that it does not: the mean annual temperature in their reconstruction rises by $1^{\circ} \mathrm{C}$ during the first half of the Holocene, then plateaus, and finally drops slightly during the past 2,000 years. This pattern is encouraging, because it closely matches a previously reported climate-model the hockey-stick reconstructions of the past two millennia.

Marsicek and colleagues also used this model simulation to show how pollen and marine proxies of surface temperature might record different aspects of the same season, and thus exhibit divergent Holocene trends. They find that cooling in the marine records parallels declining peak summer temperatures in the simulation, with changes in such temperatures being driven by declining summer insolation. Pollen-inferred temperatures, however, increase in step with the amount of heat simulated to have been received at the surface throughout the growing season, which lengthens over time because of rises in greenhousegas concentrations and cool-season insolation.

Despite these proposed differences in how the pollen and marine reconstructions record climate over short timescales, the reconstructions exhibit surprisingly similar variability over millennia: surface temperature undergoes a few oscillations of a fraction of a degree Celsius. It is unclear what to make of these fluctuations, but they resemble variability produced in the model simulation. The apparent replication of these small oscillations makes simulation $^{5}$ for the entire Holocene, as well as one wonder whether the two proxies might, in some ways, be rather precise thermometers.

Ultimately, we can have confidence in global temperature reconstructions only when they are based on comprehensive, multi-proxy data sets that span the Earth, and in which local and proxy-based noise is dampened. Marsicek and co-workers' synthesis of North American and European pollen records continues the march in this direction - these data were previously analysed within each continent to produce reconstructions ${ }^{6,7}$, but they have now been carefully joined together and compared with a model. Further progress could be made through similar efforts to mine data obtained from around the world, much as has been done to refine the hockey-stick reconstructions ${ }^{1}$.

Seasonal trends could also be better accounted for by focusing on proxies that have known seasonal biases, such as glaciers ${ }^{8}$, which often record summer temperatures, and permafrost ice wedges ${ }^{9}$, which reflect winter conditions. Moreover, reconstructions must be compared with more models, to examine how well they simulate feedbacks that could produce nonlinear responses to orbital forcing, such as the migration of the Arctic treeline $e^{10}$ or changing atmospheric dust fluxes at low latitudes ${ }^{11}$.

Finally, Marsicek and colleagues' study highlights two ways in which present climate change differs from that of the past. First, warming over the past century has occurred nearly everywhere and during all seasons, which contrasts with the more disparate spatial and seasonal trends during the Holocene. Second, if the Holocene was characterized by long-term temperature rises, as Marsicek et al. suggest, then the warming associated with human activities during the past century has probably already pushed temperatures beyond the range of temperatures that occurred during the Holocene. All the more reason, then, to improve reconstructions and models to better navigate that conundrum.

Jeremy D. Shakun is in the Department of Earth and Environmental Sciences, Boston College, Chestnut Hill, Massachusetts 02467, USA.

e-mail:jeremy.shakun@bc.edu

1. PAGES2k Consortium. Sci. Data 4, 170088 (2017).

2. Marcott, S. A., Shakun, J. D., Clark, P. U. \& Mix, A. C. Science 339, 1198-1201 (2013).

3. Marsicek, J., Shuman, B. N., Bartlein, P. J.,

Shafer, S. L. \& Brewer, S. Nature 554, 92-96 (2018).

4. Laepple, T. \& Lohmann, G. Paleoceanography 24, PA4201 (2009)

5. Liu, Z. et al. Proc. Natl Acad. Sci. USA 111, E3501-E3505 (2014).

6. Davis, B. A. S., Brewer, S., Stevenson, A. C. \& Guiot, J. Quat. Sci. Rev. 22, 1701-1716 (2003).

7. Viau, A. E., Gajewski, K., Sawada, M. C. \& Fines, P. J. Geophys. Res. 111, D09102 (2006).

8. Solomina, O. N. et al. Quat. Sci. Rev. 111, 9-34 (2015).

9. Meyer, H. et al. Nature Geosci. 8, 122-125 (2015).

10.MacDonald, G. M., Kremenetski, K. V. \& Beilman, D. W.

Phil. Trans. R. Soc. B 363, 2283-2299 (2008).

11.Albani, S. et al. Clim. Past 11, 869-903 (2015). 